27 Anderson GL, Judd HL, Kaunitz AM, Barad DH, Beresford SA, Pettinger $\mathrm{M}$, et al. Women's Health Initiative Investigators. Effects of estrogen plus progestin on gynecologic cancers and associated diagnostic procedures: the Women's Health Initiative randomized trial. JAMA 2003; 290: 1739-1748.

28 Archer DF. The effect of the duration of progestin use on the occurrence of endometrial cancer in postmenopausal women. Menopause 2001; 8: 245-251.

29 de Vries CS, Bromley SE, Thomas H, Farmer RD. Tibolone and endometrial cancer: a cohort and nested case-control study in the UK. Drug Saf 2005; 28: 241-249.

30 Archer DF, Hendrix S, Ferenczy A, Felix J, Chris Gallagher J, Rymer J, et al., for the THEBES Study Group. Tibolone Histology of the Endometrium and Breast Endpoints Study: design of the trial and endometrial histology at baseline in postmenopausal women. Fertil Steril 2007; [Epub 2 June 2007].

31 Newcomb PA, Trentham-Dietz A. Patterns of postmenopausal progestin use with estrogen in relation to endometrial cancer (United States). Cancer Causes Control 2003; 14: 195-201.

32 Greiser CM, Greiser EM, Doren M. Menopausal hormone therapy and risk of ovarian cancer: systematic review and meta-analysis. Hum Reprod Update 2007; [Epub 27 June 2007].

33 Riman T, Dickman PW, Nilsson S, Correia N, Nordlinder H, Magnusson CM, et al. Hormone replacement therapy and the risk of invasive epithelial ovarian cancer in Swedish women. J Natl Cancer Inst 2002; 94: 497-504.

\title{
Abortion is more than a debate about conscientious objection
}

\author{
Jenny Talia
}

There is nothing like reading a Daily Mail article on sex and abortion to motivate you to campaign for justice and equality in this world. ${ }^{1}$ Linked to a story on the reduction in the number of doctors performing abortions, a general practitioner (GP) said he had quit to return to work as a surgeon because he could not bear to sign a GP contract which "forced him to refer women for terminations". I might have bought the paper in France but I do not believe the said GP and I live in the same country, nor indeed that he signed the same contract as me (and thousands of others in the land). For a start, the contraception "additional services" in the new GP contract is entirely voluntary and, in any case, you really only need to have policies on emergency contraception and preconception care to earn the measly two "QOF" points. Second, if a GP signs up to this, it allows for the referral to other practitioners for unplanned pregnancies without compromising one's conscience. So maybe there are other reasons why the aforementioned GP had to quit and work as a surgeon; and before anyone gets libel-happy, I don't doubt my dear colleague is in any way short of competent.

A recent poll by a well-known GP magazine, Pulse, indicates that a quarter of GPs refuse to sign abortion referral forms, one in five do not believe abortion should be legal, and just over half want to reduce the current 24-week legal limit for abortions. Meanwhile, the latest statistics show abortion rates have been rising in England and Wales since 1970; $32 \%$ of women who had an abortion in 2005 had one or more previous abortions, this proportion has risen from $28 \%$ since 1995.3

You could argue that the best way to reduce abortions is to limit the demand by making it more difficult for women, and thus making them think twice before taking risks. Making a decision to have an abortion is difficult enough and going through with one is traumatic. I despair at the efforts that some people go to make it harder for women to exercise their rights to an abortion. I have no desire to argue with those who have conscientious objections but I fear we are all barking up the wrong tree. No one is celebrating the current rise in abortion rates with glee, not even, dare I

J Fam Plann Reprod Health Care 2007; 33(4): 243

Pastures Green, UK

Jenny Talia, MRCGP, MSc, General Practitioner suggest, the suppliers of abortion services. But is limiting the supply the only answer?

Every unplanned pregnancy that ends in abortion is a failure of health professionals; by this I mean contraception provision in all settings including general practice, community contraceptive clinics and other health services. Of course there are other players too such as schools and parents; I'll get to these another time.

Too much effort is expended on debating the rights and wrongs about abortion and not enough is done to prevent it. What proportion of conscientious objectors makes a conscientious effort to ensure men and women use contraception? Conversely, is the pro-choice contingent too lax about initiating discussions on contraception to men and women opportunistically?

Of course, there is responsibility for everyone along the chain. What I have a problem with are health professionals who not only deny the rights of women for abortion, but also refuse to offer contraception on religious and moral grounds and insist on abstention.

One of the key features of a modern and civil society is the ability to control population growth and fertility. If most of the Western world could do it, what are we doing wrong? Perhaps what it really boils down to is a strong political will, free from religious agenda, to promote better sex education in schools, better access to reliable and free contraception (including condoms) and timely access to abortion, which hopefully by then would be a rare event. This probably explains why the USA fares no better than low-income countries when it comes to fertility control.

Here is my fantasy: young men and women bombarded with sex education messages from primary through to secondary school; similar messages being widely disseminated via magazines, on radio, television soaps and reality programmes; sex education from parents; GPs chasing young adults for chlamydia screening and everyone of reproductive age to give contraceptive advice to earn them QOF points.

Am I asking for something really radical?

References

1 More young doctors oppose abortions on ethical grounds. Daily Mail, 17 April 2007.

2 Good Health viewpoint. Daily Mail, 17 April 2007.

3 Government Statistical Service. Abortion Statistics, England and Wales: 2005 (Statistical Bulletin). London, UK: Department of Health, 2006. http://www.dh.gov.uk/assetRoot/04/13/68/ 59/04136859.pdf [Accessed 15 May 2007]. 